\title{
Correlation of serum soluble Klotho with fibroblast growth factor 23 levels in chronic kidney disease patients; a single centre study
}

\author{
Yuvaraj Anand, Vijayan Madhusudan, Parthasarathy Rajeevalochana, Mathew Milly, George Deepu, \\ Abraham Georgi* \\ Institute of Kidney Diseases, Urology and Organ Transplantation, Madras Medical Mission, Chennai, India
}

\section{A R T I C L E I N F O}

Article Type:

Original

\section{Article History:}

Received: 10 January 2019

Accepted: 14 May 2019

Published online: 10 July 2019

\section{Keywords:}

Klotho

Chronic kidney disease

Residual renal function

Fibroblast growth factor

\begin{abstract}
A B S T R A C T
Introduction: Klotho is a single-pass transmembrane protein with a long extracellular domain and short cytoplasmic tail that appears to modulate aging.

Objectives: This cross-sectional investigation was conducted at a tertiary care centre to find the possible correlation of serum Klotho with various biochemical parameters in Indian chronic kidney disease (CKD) patients.

Patients and Methods: The study was conducted in 80 CKD patients ( 58 males, 22 females). Mean age was $54.21 \pm 14.08$ years (25-90 years). Participants included 55 CKD- hemodialysis (HD), 10 CKD- peritoneal dialysis (PD) and 15 CKD-non-dialysis (ND) patients.

Results: Serum Klotho (sKlotho) in CKD-HD patients ranged from 0 to $374.36 \mathrm{ng} / \mathrm{mL}$ with a mean of $13.76 \pm 4.3 \mathrm{ng} / \mathrm{mL}$ (median: $0.0174 \mathrm{ng} / \mathrm{mL}$ ). In PD patients, sKlotho ranged from 0 to $374.36 \mathrm{ng} /$ $\mathrm{mL}$ with a mean of $37.58 \pm 6.56 \mathrm{ng} / \mathrm{mL}$ (median of $0.0087 \mathrm{ng} / \mathrm{mL}$ ). In ND population, sKlotho ranged from 0 to $7.01 \mathrm{ng} / \mathrm{mL}$, with a mean of $0.73 \pm 0.01 \mathrm{ng} / \mathrm{mL}$ (median of $0.1687 \mathrm{ng} / \mathrm{mL}$ ). In CKD$\mathrm{HD}$ and CKD-PD patients, sKlotho was positively correlated with the fibroblast growth factor 23 $(\mathrm{pg} / \mathrm{mL})(P<0.001)$.

Conclusion: Serum Klotho levels show significant positive correlation with FGF23 levels in HD and PD patients. The findings of the study indicate that high Klotho and fibroblast growth factor 23 levels may be associated with worse outcomes in chronic renal failure patients.
\end{abstract}

\section{Implication for health policy/practice/research/medical education:}

Serum Klotho has emerged as a powerful player in calcium-phosphate homeostasis, contributing to the high burden of cardiovascular disease in chronic kidney disease patients. The findings of the study indicate that high Klotho and fibroblast growth factor 23 levels may be associated with worse outcomes in chronic kidney disease patients.

Please cite this paper as: Anand Y, Madhusudan V, Rajeevalochana P, Milly M, Deepu G, Georgi A. Correlation of serum soluble Klotho with fibroblast growth factor 23 levels in chronic kidney disease patients; a single centre study. J Nephropharmacol. 2020;9(1):e08. DOI: 10.15171/jrip.2020.08.

\section{Introduction}

Chronic kidney disease (CKD) is a growing global public health problem (1). However, there is paucity of sensitive biomarkers to detect early CKD and there are few specific and effective strategies to retard CKD progression to end-stage renal disease (ESRD). Klotho is a single-pass transmembrane protein with a long extracellular domain and short cytoplasmic tail that appears to modulate aging (2). Klotho is expressed the highest in the kidney, suggesting that CKD might be a state of Klotho deficiency (3). Klotho suppresses 1a-hydroxylase in the kidney to regulate calcium metabolism and participates in the regulation of parathyroid hormone $(\mathrm{PTH})$ synthesis in parathyroid glands by fibroblast growth factor 23 (FGF23) $(4,5)$. Klotho has not been extensively studied in the literature, especially in peritoneal dialysis (PD) and nonhemodialysis (HD) patients.

\section{Objectives}

Due to lack of data in Indian chronic renal failure patients regarding the relevance of Klotho, this crosssectional study was undertaken at a tertiary care centre to determine the sKlotho levels in chronic renal failure individuals and its correlation with various biochemical parameters involved in calcium phosphate homeostasis and echocardiographic findings. 


\section{Patients and Methods}

\section{Study population}

A cross-sectional study was conducted in $80 \mathrm{CKD}$ patients $(58 \mathrm{M} / 22 \mathrm{~F})$ with a mean age of $54.21 \pm 14.08$ years (2590 years). They included $55 \mathrm{CKD}$ stage $5 \mathrm{D}$ (CKD-5D) patients on HD (CKD-HD), 10 CKD-5D patients on $\mathrm{PD}$ (CKD-PD) and $15 \mathrm{CKD}$ stage 3-4 patients not on dialysis (CKD-ND). The study population comprised of patients attending the dialysis and outpatient units at Madras medical mission hospital, Chennai. There were no exclusion criteria. Informed written consent was obtained from all the patients. We collected the following data from these patients: presence of diabetes mellitus and/ or hypertension, residual renal function (urine $\mathrm{mL} / \mathrm{d}$ ), vintage and frequency of HD. HD was conducted thrice a week using polysulfone membrane, with surface area $1.3 / \mathrm{m}^{2}, 1.7 / \mathrm{m}^{2}$ and $1.8 / \mathrm{m}^{2}$ depending upon the body size. We looked at other comorbidities, such as previous cardiovascular disease, type of diet (vegetarian/nonvegetarian), serum calcium, phosphorous, $25(\mathrm{OH})$ vitamin D, intact PTH (iPTH), 2-dimensional echocardiography (to detect concentric left ventricular hypertrophy), calcification of aortic and mitral valve, left ventricular mass index $\left(\mathrm{g} / \mathrm{m}^{2}\right)$, interventricular septal thickness $(\mathrm{mm})$, and posterior wall thickness $(\mathrm{mm})$. Blood samples were drawn after overnight fasting, centrifuged for 15 minutes at $2700 \mathrm{rpm}$, separated and frozen at $-70^{\circ} \mathrm{C}$. Serum Klotho levels in the serum were analyzed using a klotho ELISA kit, which was put to a run analyser at once after collecting all the samples. FGF23 (pg/mL) levels were also obtained from a 12-hour fasting serum sample using ELISA kit by Immutopics and relationships were analyzed.

\section{Ethical issues}

The research followed the Tenets of the Declaration of Helsinki. Ethical clearance was obtained from the institutional ethical committee. Informed written consent was obtained from all the study participants.

\section{Statistical analysis}

Statistical analysis was done using SPSS statistical software version 20.0 (IBM Corporation, Armonk, NY, USA). Independent samples $t$ test was used to compare means. To look at correlations, we used Spearman's and Pearson's correlation methods.

\section{Results}

Clinical and demographic details of the patients are given in Table 1 . The measured sKlotho levels was $<1 \mathrm{ng} / \mathrm{mL}$ in $74(92.5 \%)$ patients, $1-10 \mathrm{ng} / \mathrm{mL}$ in three $(3.75 \%)$ patients and $>370 \mathrm{ng} / \mathrm{mL}$ in three $(3.75 \%)$ patients. Serum Klotho was undetectable in 31 (38.75\%) patients. Serum Klotho in CKD-HD patients ranged from 0 to $374.36 \mathrm{ng} / \mathrm{mL}$ with a mean of $13.76 \pm 4.3 \mathrm{ng} / \mathrm{mL}$. In continuous ambulatory $\mathrm{PD}$ patients, sKlotho levels ranged from 0 to $374.36 \mathrm{ng} /$ $\mathrm{mL}$, with a mean of $37.58 \pm 6.56 \mathrm{ng} / \mathrm{mL}$ (median: 0.0087
Table 1. Demographic data of patients

\begin{tabular}{llc}
\hline Parameters & Group & No. (\%) \\
\hline Gender & Male & $58(72.5)$ \\
& Female & $22(27.5)$ \\
Mode of treatment & Pemodialysis & $55(68.75)$ \\
& Non dialysis & $10(12.5)$ \\
Diabetes mellitus type 2 & Yes & $15(18.75)$ \\
Hypertension & No & $47(58.75)$ \\
& Yes & $33(41.25)$ \\
Dietary pattern & No & $67(83.75)$ \\
Previous cardiovascular & Vegetarian & $13(16.25)$ \\
disease & Non vegetarian & $20(25)$ \\
& No & $60(75)$ \\
Mitral valve calcification & Yes & $42(52.5)$ \\
& No & $38(47.5)$ \\
Aortic valve calcification & Yes & $33(41.25)$ \\
Concentric left ventricular & No & $47(58.75)$ \\
hypertrophy & Nos & $42(52.5)$ \\
\hline
\end{tabular}

$\mathrm{ng} / \mathrm{mL})$. In the CKD-ND patients, sKlotho ranged from 0 to $7.01 \mathrm{ng} / \mathrm{mL}$, with a mean of $0.73 \pm 0.01 \mathrm{ng} / \mathrm{mL}$ (median; $0.1687 \mathrm{ng} / \mathrm{mL}$ ). We observed very high sKlotho levels in three dialysis patients (2 HD and $1 \mathrm{PD}$ ) of $374.36 \mathrm{ng} /$ $\mathrm{mL}, 374.26 \mathrm{ng} / \mathrm{mL}$ and $374.36 \mathrm{ng} / \mathrm{mL}$ respectively who also had corresponding FGF-23 levels of $2423.2 \mathrm{pg} / \mathrm{mL}$, $1164.2 \mathrm{pg} / \mathrm{mL}$ and $2423 \mathrm{pg} / \mathrm{mL}$ respectively. On plotting the sKlotho levels graphically, the data was positively skewed due to three high values. The Pearson's correlation between Klotho and FGF-23 serum levels was strongly positive $(\mathrm{r}=0.853, P<0.001)$ but the scatterplot showed skewed and heteroscedastic data as shown in Figure 1. The correlation analysis was repeated.

After excluding four patients with high Klotho levels $(>5 \mathrm{ng} / \mathrm{mL})$, the resultant scatterplot is shown in Figure 2 $(\mathrm{r}=0.310, P=0.006)$. On excluding zero values in Klotho, Pearson's correlation showed a strong association with FGF $23(r=0.862, P=0.007)$.

On further analysis using the independent samples t-test, these patients were found to have high FGF$23(P<0.001)$, high phosphorous $(P=0.001)$ and low vitamin D3 levels $(P=0.075)$. There was no statistically significant association of iPTH and left ventricular mass index $(P=0.60$; Table 2). Ten patients expired in the eight months following the Klotho and FGF-23 measurement. Their mean FGF-23 and sKlotho levels were 275.28 \pm 81.5 $\mathrm{pg} / \mathrm{mL}$ and $0.026 \pm 0.057 \mathrm{ng} / \mathrm{mL}$, respectively.

Moreover, there was a significant association of left ventricular mass index with FGF-23 ( $\mathrm{r}=0.308, P=0.005)$ and sKlotho ( $\mathrm{r}=-0.23, P=0.045)$ (Spearman's correlation). Left ventricular mass index (LVMI) were classified into normal and abnormal by considering a cut off 96 for women and 116 for men (6). A binomial regression was conducted to detect the effects of significantly correlated 


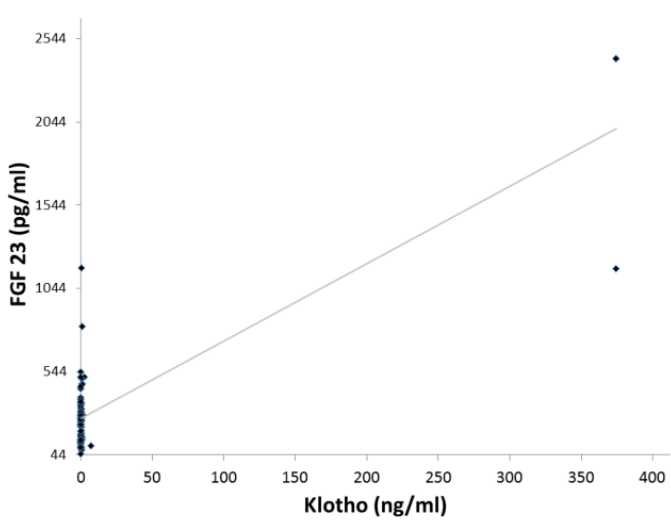

Figure 1. Scatterplot of FGF $23(\mathrm{pg} / \mathrm{mL})$ and Klotho $(\mathrm{ng} / \mathrm{mL})(80$ CKD patients).

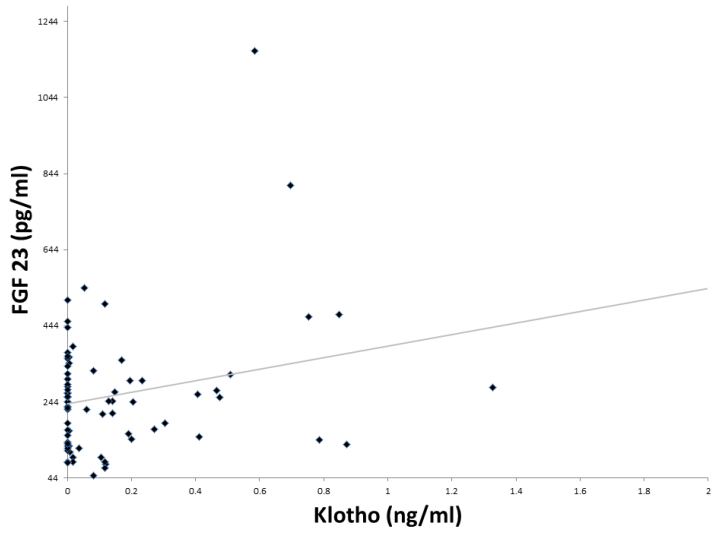

Figure 2. Scatterplot of FGF $23(\mathrm{pg} / \mathrm{mL})$ and klotho $(\mathrm{ng} / \mathrm{mL})(76$ patients; after excluding 4 patients with high Klotho levels ( $>5 \mathrm{ng} /$ $\mathrm{mL}$ ).

factors like FGF-23 and Klotho on LVMI. Out of two predictor variables, higher FGF-23 levels were significantly associated with abnormal LVMI (odds: 1.005, $P=0.031$ ).

\section{Discussion}

Klotho was originally discovered as an anti-aging factor, but the functional role of Klotho is still a controversial issue (7). Several factors, including phosphate and vitamin $\mathrm{D}$, can regulate the production of both FGF23 and Klotho and influence their functions (8). Recently, there has been experimental evidence to suggest that supplemental alpha klotho slows down the progression of $\mathrm{CKD}$ and has been tried in the treatment of acute kidney injury (9). In our study, a strong, positive correlation was found between sKlotho and FGF23 levels in CKD patients. Pathologically, increased FGF23 levels may increase the Klotho gene expression, and therefore, sKlotho expression may have increased in our patients because of an increase in FGF23 levels. Recently Inci et al have studied 109 diabetic nephropathy patients and have found a positive correlation between FGF23 and sKlotho (10).

Klotho levels are decreased in CKD, but there is paucity of data on normal levels and range in literature. Buiten et al studied $127 \mathrm{HD}$ patients, reporting a median sKlotho of $0.46 \mathrm{ng} / \mathrm{mL}$, ranging from $0.35 \mathrm{ng} / \mathrm{mL}$ to $0.62 \mathrm{ng} / \mathrm{mL}$ (11). In another study of $131 \mathrm{CKD}$ patients, wherein sKlotho was measured by ELISA showed a range from $0.163 .9 \mathrm{ng} /$ $\mathrm{mL}$ to $0.2123 \mathrm{ng} / \mathrm{mL}$, with a median of $0.759 \mathrm{ng} / \mathrm{mL}$ (12). Our study showed marked variation in the sKlotho values ranging from a minimum of 0 to a maximum of 374.36 ng/mL. Two CKD-HD patients and one CKD-PD patient had sKlotho levels $>370 \mathrm{ng} / \mathrm{mL}$ with corresponding high FGF-23 levels while such high values have not yet been reported in literature. All these three young patients underwent renal transplantation. One had a severe antibody mediated rejection (donor, mother) and the other two had graft thrombosis (donors; wife and father). They all had early graft loss within one month after initial good functioning. Hence, the role of Klotho and FGF-23 in this which again requires further clarification in future studies.

Serum Klotho has emerged as a powerful player in calcium-phosphate homeostasis, contributing to the high burden of cardiovascular disease (CVD) in CKD patients. Disorders of mineral homeostasis, as well as CVD develop in the early stages of CKD. Therefore, patients with ESRD have been exposed to an environment predisposing to

Table 2. Comparison of biochemical and echocardiographic parameters between patients who had high and low sKlotho (ng/mL) levels

\begin{tabular}{lcc}
\hline & sKlotho $>\mathbf{3 7 0}(\mathrm{n}=\mathbf{3})$ & sKlotho $<\mathbf{1 0}(\mathrm{n}=\mathbf{7 7})$ \\
\hline FGF-23 $(\mathrm{pg} / \mathrm{mL})$ & $2003.47 \pm 726.83$ & $264.18 \pm 171.57$ \\
Ejection fraction $(\%)$ & $52.33 \pm 11.15$ & $46.96 \pm 11.93$ \\
Left ventricular mass index $\left(\mathrm{g} / \mathrm{m}^{2}\right)$ & $116.67 \pm 16.04$ & $122.73 \pm 22.99$ \\
Intraventricular septum thickness $(\mathrm{mm})$ & $12.67 \pm 3.79$ & $12.96 \pm 2.54$ \\
Posterior wall thickness $(\mathrm{mm})$ & $13.00 \pm 3.61$ & $13.156 \pm 2.59$ \\
Corrected calcium levels $(\mathrm{mg} / \mathrm{dL})$ & $9.39 \pm 0.55$ & $9.115 \pm 0.91$ \\
Serum phosphorous levels $(\mathrm{mg} / \mathrm{dL})$ & $7.73 \pm 2.59$ & $5.030 \pm 1.33$ \\
Serum intact parathormone levels $(\mathrm{pg} / \mathrm{mL})$ & $244.60 \pm 28.42$ & $460.32 \pm 704.32$ \\
25-hydroxy vitamin D levels $(\mathrm{ng} / \mathrm{mL})$ & $13.83 \pm 5.75$ & $31.33 \pm 16.67$ \\
\hline
\end{tabular}


vascular calcifications for a prolonged period of time. In our study, high sKlotho level was associated with high FGF23, high phosphate and low vitamin D3 levels. Moreover, the role of sKlotho in the development of atherosclerotic disease in dialysis patients might be overshadowed by a large amount of other pathophysiological stimuli for CVD prevalent in these patients, such as smoking, obesity, diabetes and hypertension among others (11).

As reported by previous studies, our study also reported an association between FGF-23 and LV mass index (1315). A majority of our patients had a high left ventricular mass index (mean: $122.5 \pm 22.74 \mathrm{~g} / \mathrm{m}^{2}$ ), compared to previously established references for healthy men and women, which is not surprising in view of their CKD and elevated FGF-23 levels $(16,17)$. Our study mainly looked at the sKlotho and FGF-23 levels in Indian CKD patients and correlation with various biochemical parameters.

\section{Conclusion}

Klotho deficiency occurs early in CKD, starting from pre-dialysis population. sKlotho levels show significant positive correlation with FGF23 levels in $\mathrm{HD}$ and PD patients. Young dialysis patients can have very high sKlotho levels of greater than $350 \mathrm{ng} / \mathrm{mL}$. These patients also had high FGF23 levels and may be more prone to cardiovascular complications, which requires clarification from further studies.

\section{Limitations of the study}

The limitations of our study are the lack of longitudinal estimation of sKlotho levels and small sample size.

\section{Acknowledgments}

The authors acknowledge the support given by Panacea Biotec India.

\section{Authors' contribution}

YA, GA, MM, and RP designed the study. YA and DG collected the data. YA and VM wrote the paper. All authors reviewed and accepted the final version of the manuscript.

\section{Conflicts of interest}

The authors declare no conflicts of interest.

\section{Ethical considerations}

Ethical issues (including plagiarism, data fabrication, double publication) have been completely observed by the authors.

\section{Funding/Support}

None.

\section{References}

1. Perico N, Remuzzi G. Chronic kidney disease: a research and public health priority. Nephrol Dial Transplant. 2012;
27:19-26. doi:10.1093/ndt/gfs284.

2. Hu MC, Shiizaki K, Kuro-o M, Moe OW. Fibroblast growth factor 23 and Klotho: physiology and pathophysiology of an endocrine network of mineral metabolism. Annu Rev Physiol. 2013;75:503-33. doi: 10.1146/annurevphysiol-030212-183727.

3. Hu MC, Shi M, Zhang J, Quiñones H, Griffith C, Kuro-o $\mathrm{M}$, et al. Klotho deficiency causes vascular calcification in chronic kidney disease. J Am Soc Nephrol. 2011;22:124-36. doi:10.1681/ASN.2009121311.

4. Tsujikawa H, Kurotaki Y, Fujimori T, Fukuda K, Nabeshima Y-I. Klotho, a gene related to a syndrome resembling human premature aging, functions in a negative regulatory circuit of vitamin D endocrine system. Mol Endocrinol. 2003; 17:2393-403. doi:10.1210/me.2003-0048.

5. Silver J, Naveh-Many T. FGF23 and the parathyroid glands. Pediatr Nephrol. 2010;25:2241-5. doi: 10.1007/s00467-0101565-3.

6. Lang RM, Badano LP, Mor-Avi V, Afilalo J, Armstrong A, Ernande L, et al. Recommendations for cardiac chamber quantification by echocardiography in adults: an update from the American Society of Echocardiography and the European Association of Cardiovascular Imaging. J Am Soc Echocardiogr. 2015;28:1-39.e14.

7. Erben RG. Update on FGF23 and Klotho signaling. Mol Cell Endocrinol. 2016;432:56-65. doi: 10.1016/j. mce.2016.05.008.

8. Razzaque MS. The FGF23-Klotho axis: endocrine regulation of phosphate homeostasis. Nat Rev Endocrinol. 2009;5:611-9. doi: 10.1038/nrendo.2009.196.

9. Hu MC, Shi M, Gillings N, Flores B, Takahashi M, Kuro-O $\mathrm{M}$, et al. Recombinant $\alpha$-Klotho may be prophylactic and therapeutic for acute to chronic kidney disease progression and uremic cardiomyopathy. Kidney Int. 2017;91:1104-14. doi: 10.1016/j.kint.2016.10.034.

10. Inci A, Sari F, Olmaz R, Coban M, Dolu S, Sarikaya M, et al. Soluble Klotho levels in diabetic nephropathy: relationship with arterial stiffness. Eur Rev Med Pharmacol Sci. 2016;20:3230-7.

11. Buiten MS, de Bie MK, Bouma-de Krijger A, van Dam B, Dekker FW, Jukema JW, et al. Soluble Klotho is not independently associated with cardiovascular disease in a population of dialysis patients. BMC Nephrol. 2014;15:197. doi: 10.1186/1471-2369-15-197.

12. Akimoto T, Yoshizawa H, Watanabe Y, Numata A, Yamazaki T, Takeshima E, et al. Characteristics of urinary and serum soluble Klotho protein in patients with different degrees of chronic kidney disease. BMC Nephrol. 2012;13:155. doi: 10.1186/1471-2369-13-155.

13. Nassiri AA, Hakemi MS, Safar-Pour R, Ahmadi A, Tohidi M, Kashani BS, et al. Association of serum intact fibroblast growth factor 23 with left ventricular mass and different echocardiographic findings in patients on hemodialysis. J Transl Int Med. 2016;4:135-41. doi: 10.1515/jtim-20160030 .

14. Knap B, Večerić-Haler Ž, Benedik M, Buturović-Ponikvar J, Ponikvar R, Bren AF. Fibroblast growth factor 23 and left ventricular mass index in maintenance hemodialysis patients: standard versus long nocturnal hemodialysis. Ther Apher Dial. 2013;17:407-11. doi: 10.1111/1744- 
9987.12087.

15. Stevens KK, McQuarrie EP, Sands W, Hillyard DZ, Patel RK, Mark PB, et al. Fibroblast growth factor 23 predicts left ventricular mass and induces cell adhesion molecule formation. Int J Nephrol. 2011;2011:297070. doi: $10.4061 / 2011 / 297070$.

16. Cain PA, Ahl R, Hedstrom E, Ugander M, AllansdotterJohnsson A, Friberg P, et al. Age and gender specific normal values of left ventricular mass, volume and function for gradient echo magnetic resonance imaging: a cross sectional study. BMC Med Imaging. 2009;9:2. doi: 10.1186/14712342-9-2.

17. Mizukoshi K, Takeuchi M, Nagata Y, Addetia K, Lang RM, Akashi YJ, et al. Normal values of left ventricular mass index assessed by transthoracic three-dimensional echocardiography. J Am Soc Echocardiogr Off Publ. 2016; 29:51-61. doi: 10.1016/j.echo.2015.09.009.

Copyright $\odot 2020$ The Author(s); Published by Published by Society of Diabetic Nephropathy Prevention. This is an open-access article distributed under the terms of the Creative Commons Attribution License (http://creativecommons.org/licenses/by/4.0), which permits unrestricted use, distribution, and reproduction in any medium, provided the original work is properly cited. 